\title{
Evaluating beauty care provided by the hospital to women suffering from breast cancer: qualitative aspects
}

\author{
Philippe Amiel • Sarah Dauchy • Julie Bodin • \\ Céline Cerf • Franck Zenasni • Elisabeth Pezant • \\ Anne-Marie Teller • Fabrice André • Mario DiPalma
}

Received: 9 April 2008 / Accepted: 16 March 2009/Published online: 28 April 2009

(C) The Author(s) 2009. This article is published with open access at Springerlink.com

\begin{abstract} ical) the experience of beauty care by patients. care provided by hospital, 58 female, most of them treated nurses and physicians, from four French cancer centres psychologist; different types of beauty care were concerned. Results All the interviewed patients were satisfied. Patients appreciated acquiring savoir-faire on how to use make-up

P. Amiel · S. Dauchy · J. Bodin $\cdot$ C. Cerf $\cdot$ F. Zenasni •

A.-M. Teller $\cdot$ F. André $\cdot$ M. DiPalma

Institut de cancérologie Gustave-Roussy,

39, rue Camille Desmoulins,

94805 Villejuif cedex, France

E. Pezant

L'Oréal International Research,

25-29, Quai Aulagnier,

92600 Asnières, France

P. Amiel $(\triangle)$

Social and Human Sciences Research Unit,

Gustave-Roussy Cancer Institute,

Villejuif,

Paris, France

e-mail: amiel@igr.fr
\end{abstract}

Goals of work Cancer patients are offered more and more access to beauty care during their stay in the hospital. This kind of intervention has not been evaluated yet. Primary objective of our research was to determine what type of evaluation strategy to be implemented (as a supportive care with quality of life and/or medical benefits; as a service providing immediate comfort); intermediate objective was to investigate in scientific terms (psychological, sociolog-

Patients and methods Sixty patients (all users of beauty for breast cancer, two male, mean age 53 years) and 11 were included. We used direct observation and semistructured interviews, conducted by a sociologist and a and on personal image enhancement. Psychological and social well-being benefits were mentioned. The beauty care was not alleged to be reducing the side effects of the treatments, but it had helped patients to accept or bear the burden of them. Providing care beyond that which is directly curative was appreciated by the patients as a sign that they were treated as a "whole" person.

Conclusion The survey brings valuable clues concerning beauty care experience by cancer patients; it suggests the relevance of quantitative evaluation of the immediate and long-term effects on the quality of life.

Keywords Beauty care - Qualitative research · Breast cancer

\section{Introduction}

In 2002, the Gustave Roussy Cancer Institute (IGR) created a ground-breaking consultation "image advice and socioaesthetics" particularly aimed at women suffering from breast cancer. This consultation was to complement a more conventional service at the IGR offered by cosmeticians from the Cosmetic Executive Women (CEW) Association. The 'La vie de plus belle' Association (the French form of the American 'Look Good, Feel Better' programme) recently opened workshops for patients at the IGR, where they can learn to use cosmetics to preserve their physical appearance when faced with the treatment-related changes. In the IGR, as in other comprehensive anticancer centres, this service, which is offered to patients, is integrated into the supportive care provided, i.e. "all the care and support patients require in parallel with specific treatments, (...) throughout severe illnesses" $[6,7]$. The concept that these heterogeneous services group together is "beauty care". The development of such care in the comprehensive anticancer centres is in line with patient demands that were relayed by 
the associations concerned and with public policy in France aimed at fighting cancer and its consequences $[5,11]$.

Beauty care has met with vibrant success among patients themselves and has been greeted very favourably in general practitioner journals where articles have been written praising this measure. Health care establishments are being encouraged to offer this type of care to patients.

Notwithstanding, to our knowledge, this beauty care has not been precisely evaluated in the true conditions under which it is offered. Our general objective in the present study was to evaluate beauty care in the cancer setting. As a first step, our research aimed at determining the evaluation strategies that need to be implemented, considering beauty care from two points of view: as supportive care, due to its effects on objective, perceivable health (medical benefit and quality of life) and as a service providing comfort, through its effects on the experience of treatment and on the relationships between the patient and the hospital (satisfaction). An intermediate objective of this study was to document the practices of the professionals who deliver beauty care and to document the experience of patients who benefited from it. This was the basis of the empirical information required to attain the research objectives.

The qualitative empirical investigation of the experience of the people involved was conducted in quite a wide variety of situations, especially at the IGR where several heterogeneous beauty care services are offered to patients and particularly to women receiving treatment for breast cancer. The data collected confirm the relevance of this type of care in providing (psychological) support for patients while they are experiencing cancer treatment. The study suggests the relevance of quantitative evaluation of the immediate and long-term effects of beauty care on the quality of life of patients.

\section{Participants and methods}

Three groups of individuals were to be interviewed to obtain the information we were looking for:

1. Professional service providers (beauticians, image advisors ) working in a hospital where cancer patients are treated;

2. Health professionals (nurse and physician prescribers) working in these hospitals treating cancer patients;

3. Patient users treated for a breast cancer and patient users (controls) under treatment for cancer at another site.

The different services offered were:

1. Simple beauty care delivered by a cosmetician in the hospital and similar to that provided in beauty salons outside the hospital;
2. Beauty care provided by a 'socio-aesthetician', i.e. by cosmeticians having completed additional training entitling them to called 'socio-aestheticians';

3. Image advice;

4. The 'image advice and socio-aesthetics' service developed at the IGR, which combines two services in one.

Qualitative research methods were used for the survey. Qualitative research is well adapted for investigating the experience of the persons concerned, their reasons for intervening and the perceptions which shape their behaviour [4]. Two conventional techniques were used: direct observation and semi-structured interviews. These techniques have been tried and tested in multiple sociological and psychosociological surveys and have been described extensively in the literature [3].

In the case of patient users, a particular investigation programme, complementary to the main study survey, was devoted to exploring psychopathological dimensions of body deterioration on the one hand and the relationship between the patient and the beauty care service provider on the other hand. The interviews for the main survey were conducted by a sociologist (JB); the interviews for the complementary investigation were conducted by a clinical psychologist (CC).

Observations were documented in written reports. All interviews were tape-recorded with the consent of the responders and entirely transcribed. The interviews were analysed using conventional methods [9].

The members of the research team read and discussed the analyses. The results obtained from the empirical material to determine strategies for evaluating beauty care and, more generally, supportive care were likewise discussed during meetings of the research team.

\section{Results}

Survey sites and population

The survey was conducted mainly at the IGR and in three other hospitals offering beauty care to cancer patients: the Hopital Européen Georges-Pompidou (HEGP), in Paris; the Centre Hospitalier Intercommunal in Créteil (CHIC) and the University Hospital Centre in Tours (CHRU). Interviews were also conducted at Embellie, a shop in Paris specialising in products for cancer patients (wigs, make-up, external breast prostheses....etc.), which organises workshops, forums and other similar social events in which patients participate.

The distribution of the professional service providers interviewed $(n=6)$ was shown in Table 1.

Health professionals interviewed $(n=11)$ were distributed as shown in Table 2. 
Table 1 Distribution of professional service providers by job and by survey site

\begin{tabular}{llllll}
\hline & Aesthetician) & Socio-aesthetician & Image advisor & $\begin{array}{l}\text { Image advisor and } \\
\text { socio-aesthetician }\end{array}$ & Total \\
\hline IGR & 2 & - & - & 1 & 3 \\
CHIC & - & 1 & - & - & 1 \\
HEGP & - & - & 1 & - & 1 \\
CHRU & 1 & & - & - & - \\
Embellie & 1 & 1 & 1 & 1 & 6 \\
Total & 3 & & & & 1 \\
\hline
\end{tabular}

The patients interviewed $(n=60)$ were women $(58 / 60)$ and men $(2 / 60)$ receiving treatment for cancer. The average age was 53.18 years for subjects in the main survey $(n=40)$ and 48.75 years for those in the complementary survey. The distribution of responders was as shown in Tables 3 and 4 .

Among the patients interviewed, 49/60 were being treated for breast cancer and 11/60 controls were being treated for cancer at another site. They had all received beauty care. For the patients interviewed at the IGR $(n=35), 34 / 35$ were being treated for a breast cancer. All of them had received beauty care (35/35): 20/35 had received simple beauty care; $15 / 35$ had attended an "image advice and socio-aesthetics" consultation. Of these 35 patients, 20 were interviewed by a clinical psychologist, and the other 15 by a sociologist. The 20 patients interviewed by the clinical psychologist were all being treated for breast cancer (Table 5).

Interviewed patients were recruited for the main survey according to the circumstances (presence or availability of the interviewer and the patients concerned at the survey site) using the professional service provider's activity diary.

Interviewed patients were randomly selected for the additional survey at the IGR from a consultations print-out of patients recorded on this print-out (10/20) or from the professional service provider's activity diary for patients $(10 / 20)$ who were receiving simple beauty care (which is not documented on the consultations print-out).

Heterogeneous and poorly standardised services

The survey of persons providing beauty care revealed heterogeneous approaches and practices. There were four types of activity corresponding to relatively distinct jobs.
Simple beauty care services The simple beauty care provided was comparable to that offered in beauty salons. The service providers were qualified cosmeticians with a state-sanctioned diploma ( $C A P, B E P$ or high school diploma in cosmetology). In our study, the aestheticians fulfilled their duties at the IGR at the patient's beside, in the patient's room or in a dedicated beauty cubicle. The beauty care delivered included the face (skin cleansing, make-up, etc.) and other parts of the body (massage, manicure, etc.). The beauticians were paid by the CEW Association.

Socio-aesthetician services "Socio-aesthetician" services were provided by an aesthetician with a state-sanctioned diploma who had additionally taken the CODES course ("Cosmetology course with a humanitarian option") in order to be able to work in health establishments. The course held at the University Hospital Centre in Tours (Indre et Loire) is sanctioned by a professional diploma. This course is unique in France and more than 600 professionals have graduated with this diploma since 1984. Currently, 230 qualified professionals are working in France [2]. In our study, a socio-aesthetician was interviewed and followed around while on the job at the CHIC in Creteil (Val-de-Marne). Technically speaking, the beauty care was not different from that provided by the aestheticians, but the approach was broader, encompassing moral support, identified as such and a closer relationship with the medical teams. The qualified socio-aesthetician who participated in our study was paid by the hospital.

Personal image advice "Personal image advice," as that observed at the HEGP, consisted in personalised advice,

Table 2 Distribution of health professionals by job position and by survey site

\begin{tabular}{llllllr}
\hline & $\begin{array}{l}\text { Executive } \\
\text { nurse }\end{array}$ & Nurse & $\begin{array}{l}\text { Nursing } \\
\text { auxillary }\end{array}$ & Physician & Psychologist & Radiologist \\
\hline IGR & 2 & - & - & - & 1 & - \\
CHIC & 1 & - & 1 & - & - & - \\
HEGP & - & - & 1 & 1 & 1 & - \\
CHRU & 1 & 1 & 2 & 1 & 2 & 1 \\
Total & 4 & 1 & & & & 1 \\
\hline
\end{tabular}


Table 3 Patient distribution by survey

\begin{tabular}{lccr}
\hline & Main survey & $\begin{array}{l}\text { Complementary } \\
\text { psychological survey }\end{array}$ & Total \\
\hline IGR & 15 & 20 & 35 \\
CHIC & 8 & & 8 \\
HEGP & 5 & & 5 \\
CHRU & 7 & & 7 \\
Embellie & 5 & 20 & 5 \\
Total & 40 & & 60 \\
\hline
\end{tabular}

provided at the patient's bedside, on the colour of clothing and cosmetics best adapted to the patient's complexion, on make-up (teaching patients techniques to rectify the treatment-related changes in their appearance), on wigs and headbands useful for masking hair loss. The service provided did not always include beauty care (direct physical contact). Courses on personal image advice held in private training institutes are not sanctioned academically; the diplomas awarded are not state approved. The personal image advisor was a nurse and the founder of an association for the development of these services in the cancer setting [1]. Paid by the hospital for her duties as a nurse, she was a personal image consultant one day a week during her working hours.

Consultation on 'image advice and socio-aesthetics' The consultation on 'image advice and socio-aesthetics' offered at the IGR, in the same manner as simple beauty care, was provided by a socio-aesthetician who had been trained as a personal image advisor. The patients seen during consultations were women with breast cancer or young adults or adolescents who had cancer. In principle, they were all referred by the medical units. An appointment was needed for these consultations. They took place in a dedicated area composed of three rooms (an office, make-up parlor and a beauty care salon). Usually, the patients were seen several times during the few months of their period of treatment. The socio-aesthetician was paid by the hospital and was

Table 4 Patient distribution according to service received

\begin{tabular}{lccccr}
\hline & $\begin{array}{l}\text { Beauty } \\
\text { care }\end{array}$ & $\begin{array}{l}\text { Image } \\
\text { advice }\end{array}$ & $\begin{array}{l}\text { Socio- } \\
\text { aesthetics }\end{array}$ & $\begin{array}{l}\text { Socio-aesthetics } \\
\text { and image advice }\end{array}$ & Total \\
\hline IGR & 20 & & & 15 & 35 \\
CHIC & & & 8 & & 8 \\
HEGP & & 5 & & & 5 \\
CHRU & & & 7 & & 7 \\
Embellie & 5 & & & 15 & 50 \\
Total & 25 & 5 & 15 & & \\
\hline
\end{tabular}

Table 5 Distribution of IGR patients

\begin{tabular}{lccc}
\hline & $\begin{array}{c}\text { Main survey } \\
\text { (sociologist) }\end{array}$ & $\begin{array}{l}\text { Complementary } \\
\text { survey (psychologist) }\end{array}$ & Total \\
\hline $\begin{array}{l}\text { Beauty care at IGR } \\
\text { "Image advice and }\end{array}$ & 10 & 10 & 20 \\
$\begin{array}{l}\text { Socio-aesthetics" } \\
\text { consultation at IGR }\end{array}$ & 5 & 10 & 15 \\
\begin{tabular}{l} 
Total \\
\hline
\end{tabular} & 15 & 20 & 35 \\
\hline
\end{tabular}

part of the Onco-haematology Interdisciplinary Supportive Care Directorate.

The type of beauty care was, therefore, heterogeneous from one establishment to another. Practices were neither standardised nor evaluated. A choice of several services was offered exclusively at the IGR. In practice, patients were referred to one service or to another according to the habits of the health professional in the medical unit rather than according to the patient's preference.

\section{Perception of the physicians and nurses}

The medical and nursing staff $(n=11)$ did not clearly distinguish between beauty care and "socio-aesthetics" (7/ 11). On the whole (10/11), they were unable to give a precise definition of personal image advice.

Recourse to beauty care was reported to have beneficial effects on patients in terms of their comfort, psychic status and health, by all the medical and nursing staff interviewed: "Do you know, that there are patients who vomit before receiving their chemotherapy, as they are getting into the ambulance.... They shudder at the idea of returning to the hospital....There is a point when medication is pointless... This is when I think the socio-aesthetician has a role to play" (Jeannine, 59, nurse). They also reported beneficial effects in terms of the state of mind of relatives $(3 / 11)$, the patient's perception of their own personal image (3/11), a sense of their femininity (6/11) and of the state of mind....of the medical team: "When we arrive to provide nursing care, the patient is much more relaxed...Treatment can then be administered relatively easily" [Michèle, 33, nurse].

Experience and perception of patient users

Beauty care was appreciated by the patients in the light of their experience of the cancer- and treatment-related changes.

\section{Cancer- and treatment-related changes}

The patients gave accounts of their entry into the illness, spontaneously evoking the side effects of the treatments. 
The side effects of the treatments gave concrete expression to the illness. 'In fact, it is the change in my appearance [caused by the treatment] which made me become conscious of my illness' [Pauline, 50]. The illness, "announced" by the beginning of treatment, was experienced as a period of body deterioration and loss of (social and emotional) identity. The feeling of having sustained injuries was expressed by all responders. The main adverse physical effects spontaneously reported by the interviewed patients were in descending order: mastectomy, when the patient stated that it had been performed (13/40), loss of cranial/body hair, eyelashes (27/40), dry skin (15/40), fatigue (15/40), nail lesions (hand and toe; 11/40) and weight loss or gain (6/40). They also mentioned the feeling that the "way other people looked at them" had changed (23/40) and sometimes a feeling of shame for being ill, possibly mixed with guilt because of the distress inflicted on their entourage by the situation $(5 / 40)$. This change in the way people looked at them, which was felt unanimously, was not necessarily experienced in a negative manner: "I am always out," said Gisèle, 69 years old (....) "I obviously wore a wig (...). People say it really suits me. They were always giving me compliments and they were very kind. Well, it made me look different, like (...) and then you say to yourself, well yes, I do look different". There was no major difference in the replies of the interviewed women concerning these aspects, whatever the cancer site.

The complementary survey from the clinical psychology angle made it possible to explain the perception and the consequences of these effects.

Psychological investigation of the cancer-and treatmentrelated effects The physical changes were sometimes vividly expressed as 'mutilations' $(5 / 20)$ or more neutrally as 'changes' $(13 / 20)$, but they were always reported as being painful narcissistic effects. A deteriorated body image and the feeling of a loss of femininity, of dignity even, were expressed in different ways "I think," Lila said, "that the illness has caused me to no longer like my appearance....I have two sons who have never seen me without my wig because this physical deterioration of one's body caused by the illness is degrading for a person". "I no longer felt like a woman," said Pauline. The psychological and social functioning adverse effects were often expressed in similar terms, both in the initial survey and in the complementary psychological investigation. The feeling of helplessness $(9 / 20)$ in the situation was sometimes coupled with a feeling of shame $(5 / 20)$. The repercussions in terms of adverse effects on social functioning were: keeping oneself-to-oneself, shunning a negative look in others' eyes or fear of seeing such a look $(11 / 40$ and $9 / 20)$.

\section{Beauty care}

All the patients interviewed (60/60) had experienced at least one beauty care session in the hospital. In the main survey, the majority of the patients (28/40) had already experienced beauty care in a beauty salon. Eleven of the 40 patients said that they had never been to a beauty salon or only on an exceptional occasion. The hospital could, thus, provide them with their first experience of beauty care.

How they managed to find out about the beauty care and how frequently they used it Of the 60 patients interviewed, 49 mentioned the sources of information which allowed them to find out about the beauty care services in the hospital: they mentioned a single source $(38 / 49)$ or two sources of information on the subject. The medical, nursing and paramedical staff had been the main source of information (29/49). In one out of four cases (12/49), this member of staff had been the beauty care professional who provided the service. The fliers and handouts available in the units were the second source of information (14/49). Two persons had obtained their information from the Internet or the TV.

The frequency of use of beauty care services in hospital, according to the interviewed patients, ranged from one to 12 sessions, always combined with visits to hospital (consultation, hospitalisation): "We saw each other every Wednesday, when chemotherapy was administered, every 3 weeks...." (Barbara, 57). The patients said that they had attempted to adjust their medical appointment date to fit in with the availability of the beauty care appointment.

Identifying services offered The patients who had received beauty care from a socio-aesthetician (30/60) spontaneously distinguished an "added value" element compared to conventional beauty care. This added value was expressed in terms of competency concerning questions on health matters. "For example," Sandra, 48, said, "it would never have occurred to me to ask an aesthetician: 'How will my hair grow back? Am I going to lose my hair definitively?' It's not the type of question I could ask. The hair-dresser who styles my hair when I go there weekly (....), can't answer this type of question either". This "added value" was also expressed in terms of the ability to provide moral support: "The aesthetician will do her job, (cleansing the skin...). We will talk about things, I'm not saying that this doesn't happen. But in the case of the socio-aesthetician, you have both beauty care and psychology. That is the difference between them" Tamara, 39, told us. For all that, the patients who had recourse to simple beauty care in the hospital also praised the humane qualities of the aestheticians they saw in hospital and the way those cosmeticians communicated with them. 
Relationship with the professional service provider The relationship with the beauty care service provider was spontaneously expressed by the great majority of patients interviewed in the main survey (36/40). Whatever the beauty care service provider, the notions of being a good listener, being available and being kind were present in all the opinions. No negative opinion was expressed. In the complementary survey conducted from a clinical psychology angle at the IGR, the patients questioned (20/20) expressed similar opinions, once again, whatever the type of service they received. In the case of the socio-aesthetician and personal image advisor, they added notions of intimacy (10/ $10)$ and a personal coach relationship (7/10).

\section{Benefits perceived by the users and expectations}

All the interviewed patients were satisfied with their experience of beauty care in the hospital. The benefits perceived were, analytically, at two levels which were often closely connected in the patients' experience.

At the first level, beauty care was included in the range of solutions to the cancer- and treatment-related aesthetic, physical, psychological and social functioning changes. All the interviewed patient users appreciated the skin and hand care which counteracts the dryness and the make-up which gives a better complexion or which restores your eyebrows. Over and above the direct beauty care, the interviewed patients appreciated the advice (29/40), particularly on make-up (23/40), on skin problems (18/40) and on the choice of a wig (13/40). They also appreciated the durable learning experiences, acquiring know-how on how to use make-up and on personal image enhancement (24/40).

The benefits in terms of repercussions on their psychological and social well-being were also mentioned: for 24/40 patients, the beauty care was a "morale booster"; 22/40 of patients considered that their experience of beauty care had a positive effect on their relationship with their family and friends.

At the second level, beauty care was a type of psychological support, moral support which helped them feel better or not so terrible during the period of treatment. The beauty care sessions were a 'distraction' from the treatments and the illness (22/40). "My perfusion came to an end at the same time as my beauty care session. I didn't notice the time go by," said Lila, 55. "And that was very good" she added, laughing. This distraction, this "truce/respite" during the beauty care, said the patient, offered a chance to no longer be a patient, which is what Chloé, 65, expressed in the following manner: "You come because you are sick, fine, but it is totally different! This is not part of the medical unit, it's separate. If you want to have a facial, you go to a beauty salon, that has nothing to do with illnesses. Well, I myself, when I go [to the beauty care session], I say: Well I am not here as a patient. I've come to have some beauty care, to make myself look younger, to freshen up. There!"

The beauty care was not alleged to be reducing the side effects of the treatments, but it had helped them to accept or bear the burden of the treatments and their side effects (17/ 40). Lila mentioned a radiotherapy session which could take place after the beauty care appointment: "I didn't feel the radiotherapy burn so much as on Friday. And I think that that is my psyche because the radiotherapy was the same, the energy was the same". Sophie, 42, recounts how she was "apprehensive" a fortnight before chemotherapy, because of nausea, and that it took her "three days to get back to normal": "It was a vicious circle. Fewer side effects when I go to see her? no. "But, on the other hand when I saw her after [chemotherapy], there is no doubt that they didn't last so long. I mean that she made everything vanish. It helped me considerably in that way." In the case of Capucine, 49: "It gives me encouragement. I don't panic so much"

In a simple manner, the patients expressed their satisfaction that, through beauty care, they had been "treated" way beyond the requirements of directly curative medical care $(25 / 40)$.

Characterisation of beauty care Beauty care was understood as an immediate and essential solution, albeit partial, to the 'aggressiveness' of the situation, of the treatments. Beauty care services were characterised as a non-medical dimension of holistic curative care. Beauty care was perceived as a continuum, from the medical to the more medical, rather than as an opposition between medical and non-medical or between medical care and a service. Beauty care was categorised in the following manner by the patients in the main survey $(n=40$, multiple replies) as: advice, psychological support during the illness (eight), a non-medical aid to bear the burden of treatment (22), a type of care or a service which concerns the body and state of mind (18), a complement to treatment (18) and a type of treatment (four).

Patient user expectations As this was a retrospective investigation, the patients expressed their experience of the beauty care in terms of expectations. The main demand of the patients interviewed at the IGR during the main survey was better patient information concerning the availability of beauty care at the hospital (12/15).

Value of the services provided In the main survey, the perceived value of the beauty care service was broached via a question on the cost the interviewed person was prepared to pay to have such care. Thirty-seven of 40 patients replied. Twenty-two of them said they would be ready to pay for these services. Eight of the 40 patients would not have paid for the beauty care: five of them because they would not have been able to afford it and three had taken advantage of 
these services precisely because they were free of charge. Only 11 persons attributed a cost to these services if they had been obliged to pay for them; this value was comprised between 5 and $100 €$ (mean $25.20 €$, median $15 €$ ).

\section{Discussion}

Our results are based on a qualitative study. The absence of literature on the evaluation of beauty care in the hospital justifies an exploratory step towards defining an evaluation strategy. The following limits of the methodology used must be taken into account.

Firstly, the interviewed patients recruited for the main survey cannot be considered as a representative sample of the population receiving beauty care in hospital. Thus, some attitudes may be under- or over-represented in our results. However, quantitative representativity was not the issue in this study, and on the contrary, a qualitative exploratory investigation is recognised as a way of maximising small heterogeneous samples in order to identify the widest diversity of situations which could subsequently be counterbalanced by a quantitative investigation $[8,10]$. In any case, if the figures we used to present the results enabled us to avoid subjective expressions, such as 'some', 'many' and 'most', they are not generalisable measures. Secondly, the interviewed patients were under treatment, which enabled us to investigate their immediate experience, but this survey did not provide enough elements to appraise the long-term effects of the beauty care. Finally, our results provide answers and suggest that further evaluative research should be conducted.

As might have been expected, beauty care in the hospital is considered favourably by patients treated with chemotherapy and faced with side effects affecting their hair, skin, nails and their appearance in general. In this respect, the cancer site appears to be less determinant than the type of side effects experienced. The fact that the hospital provides care for patients beyond that which is directly curative is appreciated by the patients as a sign that they are treated as a "whole" person. Beauty care helps patients live through the period of treatment better or less difficultly. It gives rise to approbation and satisfaction. Based on this, it can be said that beauty care fulfils the humanising and facilitating effects that the patients and the proponents of this measure (associations and institutions) expected.

For all that, the study opens as many research avenues as it provides answers. Thus, for people who have recourse to beauty care, where it is offered, one needs to know whether a demonstratable effect, in terms of quality of life, can be established, and if the effect is positive, how durable it may be? One also needs to know whether this possible effect is specific to beauty care or whether it can be obtained, to the same extent, with other types of supportive care (sophrology, relaxation, tai chi chuan...) A further question in a situation of equality of access, is whether the choice of having or not having beauty care is dependent or not on factors (psychological, particularly coping strategies) which would independently be predictive of a better or poorer quality of life during and after the treatment.

An evaluative research strategy would aim to measure the benefits that cancer patients receiving beauty care claim to enjoy, to determine the specificity of this care in giving rise to these alleged benefits and to identify the determinants of having recourse to or not having recourse to the beauty care offered.

On that basis, a prospective, randomised trial is ongoing to assess the value of beauty care at improving patients' quality of life.

Acknowledgment We are greatly indebted to the patients and health professionals who agreed to be interviewed for this study. We thank Ms. Clara Ughetto for transcripting the interviews and Ms. Lorna Saint-Ange for translations to English.

Funding/Support This study was funded by Recherche L'Oreal.

Open Access This article is distributed under the terms of the Creative Commons Attribution Noncommercial License which permits any noncommercial use, distribution, and reproduction in any medium, provided the original author(s) and source are credited.

\section{References}

1. Apima (Apprivoiser son image dans la maladie [Taming your Image in Illness]) http://www.apima.fr/. Accessed 13 sept 2007

2. Codes (Cours d'esthétique à option humanitaire [Humane Beauty Care School] http://www.chu-tours.fr/site_public/chu/CODES/ codes.htm\#3. Accessed 13 sept. 2007

3. Denzin NK, Lincoln YS (2000) Handbook of qualitative research. Sage, Thousand Oaks

4. Greenhalgh T, Taylor R (1997) How to read a paper: papers that go beyond numbers (qualitative research). BMJ 315:740-743

5. Khayat D, Kerr D (2006) A new model for cancer research in France. Nat Rev, Cancer 6:645-651. doi:10.1038/nrc1927

6. Klastersky J (1993) Supportive care in cancer patients. Lung Cancer 9:397-404

7. Krakowski I, Boureau F, Bugat R, Chassignol L, Colombat P, Copel L, D'Hérouville D, Filbet M, Laurent B, Memran N, Meynadier J, Parmentier G, Poulain P, Saltel P, Serin D, Wagner JP (2004) Coordination des soins de support pour les personnes atteintes de maladies graves : proposition d'organisation dans les établissements de soins publics et privés [For a coordination of the supportive care for people affected by severe illnesses: proposition of organization in the public and private health care centres]. Bull Cancer 91:449-456

8. Kuzel AJ (1992) Sampling in qualitative inquiry. In: Crabtree BE, Miller WL (eds) Doing qualitative research. Sage Publications, Newbury Park, Calif

9. Miles M, Hubermann A (1994) Qualitative data analysis: an expanded handbook, 2nd edn. Sage, London

10. Morse JL (1992) Qualitative nursing research: a contemporary dialogue. Sage, Newbury Park

11. Plan cancer [French national cancer plan] http://www.plancancer. fr. Accessed 13 Sept. 2007 